Avances y resultados de investigación

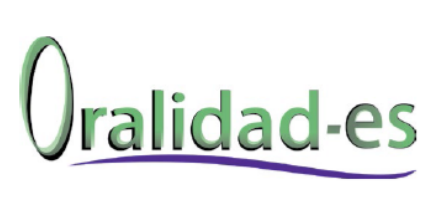

REVISTA DE LA RED IBEROAMERICANA DE ESTUDIOS

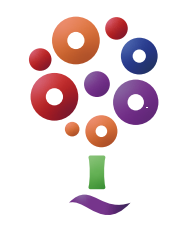

\title{
La música reggae en Panamá. Breve reseña histórica
}

\author{
Reggae music in Panama. Brief historical review
}

\author{
Guillermina Itzel De Gracia \\ guillerminaitzeldegracia@gmail.com \\ Quality Leadership University, Panamá
}

Itzel De Gracia, G. (2018). La música reggae en Panamá. Breve reseña histórica. Oralidad-es, 4, 1-15. https://revistaoralidad-es.com/index.php/ro-es/article/view/103/74

Fecha de recepción: 17 de enero de 2018 / Fecha de aceptación: 24 de junio de 2018

() (1) 


\section{Resumen}

En 1985, cuando Leonardo Renato Aulder sacó a la luz por primera vez la canción titulada ¿Qué es lo que el D.E.N.I. puede hacer? las radios emisoras panameñas se transformaron y es muy probable que nadie, en ese momento, tuviese idea de la revolución musical que esto ocasionaría. Renato (como sería conocido a partir de ese momento) se convertiría en el primer panameño en grabar este género en español, que a lo largo de estas tres últimas décadas se ha propagado por el mundo y ha sido la génesis de nuevos géneros musicales.

En Panamá nace un género musical distinto, pero que comparte un mismo contexto cultural con Jamaica. A lo largo de su historia el reggae en español ha impactado muchas partes de América Latina y ha acumulado tanto simpatizantes como detractores.

Este artículo desmenuza los inicios de esta música en Panamá, analizando las características históricas y culturales que hicieron que este país no solo fuese el primer lugar donde se produjo y comercializó el reggae en español, sino también donde surgieron el calypso, el kompas o el haitiano, en ese idioma.

\section{Palabras clave}

Música popular; cultura; jamaica; panamá; reggae en español

\section{Abstract}

In 1985, when Leonardo Renato Aulder brought out for the first time the song entitled ¿Qué es lo que el D.E.N.I. puede hacer? Panamanian radio stations were transformed and probably nobody, at that moment, had any idea of the musical revolution that this would cause. Renato (as he would be known from that moment) would become the first Panamanian to record this genre in Spanish, which over the last three decades has spread throughout the world and has been the genesis of new musical genres.

In Panama a different musical genre is born, but it shares the same cultural context with Jamaica. Throughout its history, reggae in Spanish has impacted many parts of Latin America and has accumulated both supporters and detractors.

This article breaks down the beginnings of this music in Panama, analyzing the historical and cultural characteristics that made this country not only the first place where reggae was produced and marketed in Spanish, but also where the calypso, the kompas or the Haitian arose, in that language.

Key words:

Popular music; culture; jamaica; panama; reggae in spanish 
"Hay muchísima gente que piensa que uno puede sufrir para hacer música. La música es vida, escribes sobre cómo te sientes, no como los demás imaginan que deberías sentirte”. Bob Marley

\section{El movimiento Rastafari y el Reggae}

Los procesos que se pretenden analizar y describir en este artículo son eminentemente culturales. Esto hace pertinente definir lo que los antropólogos sociales entienden por cultura. Así, para los efectos del presente trabajo, cultura es (...) "el conjunto complejo de información no hereditaria, acumulada, conservada y transmitida por múltiples colectividades de la sociedad humana" (Bohannam, 2009), que incluyen las creencias religiosas, la música, la danza, la literatura, la indumentaria, los modos de mesa y otros tantos atributos conductuales humanos.

El movimiento Rastafari ${ }^{1}$ es considerado una religión ${ }^{2}$ que tiene sus orígenes en el continente africano, con claras orientaciones políticas y cuya característica principal es no aceptar los valores impuestos por la ideología dominante. Desde la perspectiva del ideólogo Marcus Garvey: "Somos un pueblo decidido a no sufrir más. Etiopía es la tierra de nuestros Padres" 3
Este movimiento tiene un contexto histórico claramente definido, y es que en 1930 más de 20,000 jamaiquinos volvieron a su país en busca de empleo y un nuevo sentido de identidad, después de haber cumplido con sus contratos de trabajo en Panamá y Cuba. El impulso del Rastafarismo inició con tres repatriados: Leonard Howell ${ }^{4}$, Archibald Dunkley y Joseph Hibbert; cada uno empezó a propagar la divinidad de Ras Tafari Makonnen, coronado como Emperador de Etiopía. Esta religión tiene como fundamento la creencia de que Dios encarnó en Haile Selassie $\mathrm{I}^{5}$, conocido primeramente como Ras Tafari Makonnen.

Su fin último es la emancipación del pueblo negro, al cual consideran la reencarnación de las tribus perdidas de Israel, cuya redención se producirá con el éxodo hacia África guiados por Dios $(J a h)^{6}$. Allí se alcanzará el cielo en la tierra y los negros tendrán superioridad. A su vez, este movimiento incorpora elementos religiosos africanos y narraciones del Antiguo Testamento Judeo Cristiano.

Los orígenes del Rastafarismo no están relacionados directamente con el inicio del reggae. Sin embargo, el reggae se ha convertido para los rastas en una forma de expresión religiosa que les permite manifestarse en contra de la ideología imperante, tal y como demostró Bob Marley, considerado el máximo representante del género y quien compartía las creencias rastafaris.

\footnotetext{
${ }^{1}$ Jorge J. Giovannetti en su libro "Sonidos de Condena" sostiene que: "El movimiento Rastafari recoge influencias de toda una serie de expresiones de históricas de resistencia que van desde la esclavitud y el bedwardismo hasta la ideología de Marcus Garvey. En síntesis, sus postulados se han de resumir como los siguientes: 1) la creencia en la divinidad de Haile Selassie I, emperador de Etiopía; 2) la visión de África como la tierra prometida (Zion) y de Jamaica como el lugar de perdición (Babilonia) y 3) la visión del pueblo negro jamaicano como la reencarnación del pueblo de Israel, sufriendo el exilio a Jamaica” (2001, p 43). George E. Simpson (1955) “The Ras ${ }^{2}$ Tafari Movement in Jamaica: A Study of Race and Class Conflict" Social Force, 34:2

Para profundizar en el tema se sugiere leer Ulloa Brenes, Gilbert (2007). Hipótesis sobre la subversión religiosa en el Rastafarismo. Revista Reflexiones 86-1. Páginas 115-126. Costa Rica.

${ }^{3}$ Comunidad Rasta Panameña. Manuscrito no publicado. pp.15

${ }^{4}$ Leonard Howell dirigió de 1940 a 1945 un grupo denominado Pínchale, formado por 1600 seguidores

${ }^{5}$ Nombre que significa Poder de la Trinidad. Manuscrito no publicado. Comunidad Rasta de Panamá. p15.

${ }^{6}$ Jah. Nombre de Dios en su septuagésima segunda encarnación en la tierra, la persona de Haile Selassie I. Su nombre invoca el poder del Todopoderoso. Salmo 68:4 "Cantad a Dios, cantad salmos a su nombre exaltad al que cabalga sobre los cielos. Jah es su nombre; alegraos delante de Él”.
} 


\section{La Música Reggae}

El siglo XX se caracterizó por el deseo de muchos grupos étnicos, históricamente oprimidos, en alcanzar un mejor estatus dentro de la sociedad, conduciéndoles a crear congregaciones. Para el grupo negro, no es sino a mediados del siglo XX cuando se dieron las condiciones sociales e históricas para, como confirma el sociólogo panameño Gerardo Maloney, sucediera "la lucha de los negros por la conquista de su igualdad, la reivindicación de la cultura y los valores de los negros del mundo, ...que inspiraron a hombres como Luther King, Malcom X, Elridge Cleaver, Angela Davis, a organizaciones como Las Panteras Negras a una titánica empresa histórica".

Los orígenes del reggae pueden ubicarse a mediados de la década de los cincuenta del siglo pasado, cuando, debido a la cercanía que había entre las islas caribeñas y el sur de los Estados Unidos, se propició una migración desde los incipientes e inestables estados isleños hacia la potencia del norte. Fue entonces cuando los ritmos norteamericanos y caribeños, con antecedentes africanos, produjeron el reggae, donde el ritmo de la música se vuelve más lento, los tiempos débiles son cada vez más marcados y predomina el bajo ${ }^{8}$. En sus inicios no era música de carácter religioso, sino parte de la evolución musical de la época.

La palabra reggae se comenzó a utilizar gracias a las canciones Manny Goat, y más adelante Do The Reggae, del conjunto musical Toots and The Maytals, que según explicaciones del propio Toots, se refiere a regular (regular people o la gente normal, de a pie, de la calle). Sin embargo, existen varias explicaciones del origen de la expresión reggae, así tenemos que: "Para algunos, el término Reggae se deriva de Regga, el nombre de una tribu Bantú del Lago de Tangañica. Para otros, reggae es una derivación del lenguaje popular de Kingston "Streggae", que significa prostituta. Sin embargo, para el propio Bob Marley viene del español y significa Música de Reyes".

El reggae para muchos músicos proviene de la música Burru (antiguo culto africano convertido en música profana de los guetos). Ésta era la música que practicaban los negros durante la esclavitud. Los instrumentos utilizados eran tres tipos de tambores: bajo, tenor (fundah) y repicador. ${ }^{10}$

Con el transcurrir del tiempo, el reggae, se convirtió en la música más representativa de Jamaica; nació y se desarrolló de la mano de los herederos de los esclavos africanos, y gracias a los disc-jockeys, el reggae se propagó por toda la isla de Jamaica. Estos individuos recorrían este territorio en toda su extensión a bordo de camionetas, transportando discotecas móviles, con esta música como principal atracción.

El género musical pronto conquistó la Isla, con intérpretes como Jimmy Cliff, gracias a la película Harder They Come y Bob Marley and The Wailers. Las primeras producciones de artistas jamaiquinos fueron realizadas por compañías disqueras británicas como Melodisc, Bluebeat y Island.

El género musical pronto conquistó la Isla, con intérpretes como Jimmy Cliff, gracias a la película Harder They Come y Bob Marley and The Wailers. Las primeras producciones de artistas jamaiquinos fueron realizadas por compañías disqueras británicas como Melodisc, Bluebeat y Island.

\footnotetext{
${ }^{7}$ Maloney, G., 1992

${ }^{8}$ Leymarie, I. 1985 . pp. 76

${ }^{9}$ Maloney, G. 1992.

${ }^{10}$ Ibidem.
} 
Las ideas rastafaris seducen a los "rode boy" o "chicos malos" y a numerosos músicos de reggae como Desmond Bekker, Burging Spear, Gregory Issac, Pablo Moses y Ras Michael. Count Ossie, el percusionista rasta, introduce en el reggae los tambores del burru y el repeater, tambor solista del nyabinghi (facción militante de los rastas). Los ritmos nyabinghi serán extrapolados también a otros instrumentos. El reggae adopta también los ritmos (riddims) de las ceremonias rastas y de la iglesia revivalist. ${ }^{11}$

Antes del reggae, el ritmo más representativo de Jamaica era el $S k a^{12}$, pero el reggae comenzó a agregarle importancia a su base musical y rítmica con la participación del requinto y el bajo, que no mantenía el Ska. Sin embargo, la verdadera transformación se cifró en las letras de las canciones. Estas comenzaron a reflejar situaciones sociales, con un cargado y manifiesto sentido de protesta.

Esta música es reflejo del profundo descontento social al que se vieron sometidos los descendientes y herederos de la cultura africana implantada en Las Antillas, que aún prevalece, a pesar de los obstáculos colonialistas y postcolonialistas que intentaron exterminarla y la marginaron a los estratos más bajos de la sociedad jamaiquina.

Es por esto y por muchas razones más que para los Rastamen, el reggae:

"Es el reflejo de una raza y una cultura, de sus sentimientos, ideas anhelos, alegría y dolores. Es una raza que a pesar de todo no deja de cantar su alegría por vivir" ${ }^{13}$

\section{Los cambios en la música Reggae}

La música reggae ha pasado por diferentes cambios. Predecesores y descendientes de este género musical han aportado, adaptado, deteriorado, modificado y comercializado el reggae en más de un concepto. El reggae es la forma de expresión de los rastafaris, sin embargo, es importante destacar que el reggae no es un género exclusivo de la creencia rastafari y no todos los que cantan reggae son rastamen ${ }^{14}$.

Los cambios en los géneros musicales son una constante en la historia de la música. El reggae no ha escapado a esta tendencia, de manera que este género se ha visto influido, en los últimos años, por otros ritmos que lo han diversificado, produciendo algunos cambios en su música y "lirica", que para muchos han sido un tanto drásticos.

En Jamaica ${ }^{15}$, este género musical comprende dos grandes tendencias, a saber:

Reggae roots: La traducción literal seria la "raíz del reggae". Cuando se habla de reggae roots se hace referencia al reggae utilizado en su mayoría por las personas o grupos influenciados por las ideologías rastafaris. Es un reggae para meditar, cuyo contenido transmite ciertos juicios y normas claramente definidos.

Dancehall music: La universalización del reggae de alguna manera fue distanciándolo de los sectores populares de Jamaica y creó la apertura para una corriente más

\footnotetext{
${ }^{14}$ En Jamaica, en Panamá y en el mundo.

${ }^{12}$ El Ska tiene sus inicios en la década de los 60' en bandas como Skatiles, Desmond Dekker, Prince Buster (y hasta Bob Marley), lo que después llevó al reggae. El Ska regresó a finales de los 70’ en el Reino Unido. Como Jamaica formaba parte de la mancomunidad británica, los inmigrantes esparcieron la música, y la popularizaron bandas como The Specials, Mandes and the Selecter. Estas bandas también añadieron un sonido de rock punk al Ska, mientras que aceleran su ritmo. El Ska se popularizó en los Estados Unidos con bandas como Toasters, Fishbone, y la NY Citizens.

${ }^{13}$ Comunidad Rasta de Panamá, op cit., pp. 25.

${ }^{14}$ En Jamaica, en Panamá y en el mundo.

${ }^{15}$ Para efectos de esta investigación se hablará solo de las corrientes de música reggae que han surgido en Jamaica, por que son ellas las que han formado e influenciado en la música reggae nacional.
} 
original, más popular, por su lenguaje y filosofía. Esa corriente se llamó Dub Music (... ${ }^{16}$ Esta música que permitía a las personas bailar, tiene un sonido característico que parece rap con acento jamaiquino; ya tiene unos 40 años y para muchos es el reggae que expresa la realidad de los ghettos, llenos de armas, superpoblado y vació de oportunidades y de esperanza. Cuenta la historia de las realidades jamaiquinas en las calles y brindó oportunidades a muchos jóvenes de los barrios populares para superarse.

\section{De Jamaica a Panamá. Un sitio para el reggae en español}

A su llegada a Panamá, en 1985, el reggae se ejecutaba y bailaba en diferentes lugares llamados o conocidos como toldos ${ }^{17}$ populares. Esta música era parte del repertorio que incluía: salsa, merengue y música "típica” panameña. Entre los toldos que se destacaron durante los primeros años de vida de este género estaban: El Sesteo en San Miguelito, Los Compas en Pedregal y el Súper Centro Caribe en calle 8 y 9, Ave. Central y el Club Náutico Caribe en la ciudad de Colón.

Si se analizan los lugares en que se afianzó este género, se puede observar claramente que, en sus inicios, esta música estaba muy ligada a las ciudades terminales de Panamá y Colón, especialmente a sus barrios menos favorecidos. No obstante, con el pasar de los años, se extendió a las discotecas estables ubicadas a lo largo de la Vía España, el Centro Comercial El Dorado y otros lugares a los que asistían personas pertenecientes a la denominada como clase media-alta.

¿Qué permitió al reggae llegar para quedarse? Se considera que el reggae alcanzó un gran desarrollo gracias a que sus letras reflejaban las realidades sociales en que estaban inmersos muchos de sus cantantes, oyentes y seguidores. Este es uno de los motivos por los que, después de más de tres décadas de vida, el reggae sigue estando entre los géneros musicales favoritos de los panameños. Aunado a esto, se puede mencionar la influencia que, sobre su desarrollo y afianzamiento, tuvo y tiene la realización de grandes conciertos, con cantantes extranjeros de reggae, entre los que se incluyen: Yellow $\mathrm{Man}^{18}$, TOK, Shaggy y The Wailers ${ }^{19}$. Definitivamente en $\mathrm{Pa}$ namá el reggae se ha convertido en una mercancía productiva para la economía nacional.

¿Por qué fue en Panamá dónde se comenzó a cantar reggae en español y qué características posee este espacio geográfico que ha permitido que se haya incorporado a su cultura y permanezca?

La respuesta a esta y a otras interrogantes similares sólo puede ser contestada a la luz de las ideas del apóstol de la nacionalidad panameña, el Doctor Justo Arosemena, para quién la realidad física de Panamá está basada en su separación geográfica, histórica, etnográfica y social, tanto de lo que hoy denominamos Centroamérica, como de Suramérica. Su visión puede interpretarse como compuesta por un doble eje de coordenadas perpendiculares, que indica las continuidades y rupturas que nos acercan o nos separan de los cuerpos geográficos antes mencionados. (Arosemena,1855, pp.215-296)

\footnotetext{
${ }^{16}$ Giovannetti, Jorge L. (2001) Sonidos de Condena. Sociabilidad, historia y política en la música reggae de Jamaica. Siglo XXI Editores. México

${ }^{17}$ En Panamá, al igual que en Jamaica, la música reggae se propaga por todos lados, gracias a grandes sistemas de sonido, estos equipos móviles es uno de los elementos fundamentales en el desarrollo de este género (Giovannetti,2007). Estas grandes bocinas se colocaban en Toldos: Salones de bailes improvisados (muchas veces), donde se hacen bailes populares.

${ }^{18}$ https://www.panamaamerica.com.pa/ey/yellowman-incansable-luchador-997657

${ }^{19}$ Banda original del Cantante de reggae roots Bob Marley, se presentó en Panamá el año 2003.
} 
El eje de dirección este-oeste del Istmo, indica su separación respecto al resto de Suramérica y su límite Arosemena lo ubica en el Río Atrato (Arosemena,1855, p. 233). El eje perpendicular corre de norte a sur y une a Panamá con Las Antillas.

Se ha reconocido que este último eje determinó, durante gran parte del siglo XX, que Panamá junto con Las Antillas Mayores, constituyera el arco estratégico que sirvió de protección el cuerpo sur de nación norteña. Y más remotamente, la vía de paso de riquezas y productos, hacia y desde La Española, con destino final en la metrópoli ${ }^{20}$. El resultado fue, en gran medida, que alrededor del área canalera se desarrollara un pueblo con características socioeconómicas que Arosemena denominó marítimo mercantil (Arosemena,1855, p. 233). Esta continuidad geográfica, cultural y económica que Panamá creó con el resto del Caribe, explica en gran medida que el reggae haya encontrado aquí un medio adecuado para su desarrollo y expansión. Se puede demostrar que la relación musical entre nosotros y el resto del Caribe es larga (García Hudson, 2012).

Así se tiene, y solo por dar un repaso a la historia musical de Panamá, que el gran compositor de jazz, Luis Carl Russell (1902 - 1963) nació en Bocas del Toro donde estudió guitarra, violín y piano. Tras una breve estadía en Colón, donde formó parte de una banda de músicos profesionales, de los cuales se separó para realizar una larga y prestigiosa carrera como creador del último desarrollo del jazz, conocido como estilo de New Orleans (Wolfschoon, 1983, pp. 37-67)

El cantante de Rumba cubano, Miguelito Valdés, inició su destacada carrera en Panamá. Igualmente, Panamá ha generado compositores de bolero de estatura continental, como son Carlos Eleta Almarán y Arturo Hassán (Chino) ${ }^{21}$. En esta apretada síntesis hay que recordar que durante las décadas de los 50 y 60 una generación impor- tante de afroantillanos compuso y ejecutaron, con calidad variable, un importante repertorio de calipsos, sobresaliendo Lord Cobra y Lord Panamá. En períodos más recientes, resaltan mucho los nombres de Rubén y Roberto Blades quienes han destacado como creadores e intérpretes de salsa caribeña.

No todos aceptarían la tesis antes planteada, pues para algunos el reggae se ha mantenido interrumpidamente en Panamá gracias a la existencia de productores nacionales que se han encargado de su elaboración y distribución. Sin embargo, fue mucho después de su llegada, aproximadamente en 1995, cuando el reggae comenzó a apreciarse por su valor mercantil. Consistentemente con esta interpretación, se puede reseñar que los primeros cantantes de reggae habitaban en barrios populares de las ciudades de Panamá y Colón y descendían de la colonia afroantillana, ubicada en esas ciudades desde la construcción del Ferrocarril primero, y del Canal Interoceánico después (Díez, 1981).

No es de extrañar entonces, que el reggae panameño naciera en esa porción de la República, tanto como que en Jamaica lo hiciera en los llamados guetos de Kingston (Giovannetti,2001). Ni tampoco es trivial, que sea a través de las canciones de reggae, que estos grupos dieran a conocer la forma de vida y la realidad social que los identifica.

Se postula entonces que algo muy similar pasó en Panamá, dada la proximidad geográfica y las similitudes sociales y étnicas que identifican a nuestros barrios populares con sus símiles jamaiquinos; realidad que era expresada de forma amena y contagiosa mediante las letras y melodías del reggae.

\footnotetext{
${ }^{20}$ Para una visión más detallada de este componente ver Bosch, J. 1981.

${ }^{21}$ Ver Caja de Ahorros, 1972, y I. M. Zabala, 2000.
} 


\section{¡Con las manos arriba y empujando!}

Los antropólogos sociales se preguntan acerca de cómo formas culturales poco difundidas, lentamente alcanzan una preeminencia inusitada, hasta que finalmente sustituyen, casi de forma espontánea, cualquier otra creación cultural.

El fenómeno reggae pertenece a esta categoría misteriosa de fenómenos culturales que se pueden estudiar in situ (en Panamá) por la existencia de sus protagonistas, quienes fueron entrevistados y por lo abundante del material documental, existente en forma de videoclips, grabaciones, discos compactos, programas radiofónicos y sesiones de los disc-jockeys (DJs).

Así se han podido deducir los mecanismos de difusión que han permitido al reggae panameño mantenerse por más de dos décadas consecutivas como la forma cultural dominante de la subcultura juvenil. Durante la década de 1980 en el interior de la sociedad panameña, existía una gran aceptación de variedad de géneros musicales, entre estos se destacan: la salsa de Puerto Rico, el merengue de República Dominicana y el kompás o haitiano de Haití.

Es bajo este amplio espectro musical que el género reggae originario de Jamaica, llegó a nuestra tierra alrededor de 1985, y se incorporó al gusto musical de los panameños ${ }^{22}$.
Se considera por muchos la canción Don't bend Down (No te agaches), vocalizada por el intérprete jamaiquino Lovindeer y difundida por las emisoras y discotecas móviles, como el boleto de entrada de este género en Panamá; que no tardó en ser sometido a cambios en el ritmo.

Otro evento concomitante es el desarrollo de la corriente dancehall, como la forma musical dominante en Panamá.

\section{El dancehall se canta en español}

El dancehall ${ }^{23}$ jamaicano clásico se incorpora rápidamente a los gustos de los jóvenes panameños; quienes en su gran mayoría no entendían las letras de lo que se cantaba, ya que eran cantadas en inglés. Sin embargo, esto no frustró la introducción del género.

Leonardo Renato Aulder conocido como Renato canta, en 1985, el primer dancehall en español, titulado “¿Qué es lo que el D.E.N.I ${ }^{24}$ puede hacer?", que lo convirtió en el primer dancehall en español, y a Panamá, en la llamada "cuna del reggae en español”25. Este primer producto nacional, no obstante, fue una traducción de la versión jamaiquina del sencillo titulado "What' hell the police can't do?"26, aunque ambientada a la realidad nacional ${ }^{27}$.

\footnotetext{
${ }^{22}$ Sin embargo, es de suponer que los primeros inicios del reggae en Panamá estén representados por la corriente roots, (Bob Marley, principalmente dado a una nutrida colonia étnica de procedencia jamaiquina que se ubicó aquí para la Construcción del Canal, pero eso no será analizado en esta investigación.

23 “En la Jamaica de los años noventa, el reggae ya no era el género que estaba en primer plano, a partir de los años ochenta había sido reemplazado por la música dancehall. Este nuevo género es de un ritmo más rápido y agrupa influencias del variado repertorio de expresiones musicales jamaicanas, además de los modernos ritmos de la 'cultura pop' internacional, muy especialmente del hip-hop y el rap estadounidense" (Giovannetti, 2001, p. 68)

${ }^{24}$ D.E.N.I. Siglas del Departamento Nacional de Investigaciones de las Fuerzas de Defensas de régimen dictatorial del General Manuel Antonio Noriega

${ }^{25}$ Ver video del Sr. Rodney Clark productor musical https://www.youtube.com/watch?v=YQFsnVk7bm8

${ }^{26}$ Cantada por el cantante jamaicano Lloyd Lovindeer conocido como Lovindeer.

${ }^{27}$ Leonardo Renato Aulder. "Yo trabajaba para una discoteca móvil con el Señor Reggae San y comencé a cantar con ellos". Comunicación personal.
} 


\begin{tabular}{|l|l|}
\hline ¿Qué es lo que el D.E.N.I puede hacer? & What' hell the police can't do? \\
Renato & Lloyd Lovindeer \\
\hline $\begin{array}{l}\text { Policia: Tú me quieres decir que él te pegó y te } \\
\text { hinchó el ojo así. }\end{array}$ & TOC TO TOC \\
Mujer: Si y me dijo que el D.E.N.I. nada puede & ¿Quién es? \\
hacer. & La Policia \\
TOC TOC TOC & "el chico azul" Ohhh Así es que tú eres el tongo \\
¿Quién es? & que está causando este alboroto en mi relación. \\
La policía. & Rapeo: Soy chocolate me llaman "el chico azul" \\
Rapeo: Yo soy renato comisario con poder, te \\
voy a enseñar lo que el D.E.N.I. puede hacer. \\
Yo puedo llegar en mi LCD gritarte en español \\
y también en inglés y empujarte duro contra la la \\
pared y a punta de palo tú vas a aprender. \\
$\begin{array}{l}\text { Yo puedo por liso darte un bofetón o por inde- } \\
\text { cente meterte un patadón (...) }\end{array}$ & $\begin{array}{l}\text { guntarte qué demonios la policía puede hacer. } \\
\text { Vine a mostrarte lo que la policía puede hacer }\end{array}$ \\
\hline
\end{tabular}

El dancehall music es llamado por la comunidad panameña como reggae o rapeo y contó entre sus cultores, además de los de origen nacional, con figuras jamaicanas como Yellow Man, Papa Sam, Cocoa Tea, Shabba Ranks, entre otros; estos últimos venían a Panamá a realizar conciertos. Es así como comienza la historia de uno de los géneros musicales más controvertidos en la sociedad panameña y que ha desatado un sin número de reacciones, manteniéndose en este país por más de tres décadas consecutivas.

\section{Los cantantes de "el patio"}

El nuevo género se introduce rápidamente en el mercado nacional. Los intérpretes llamados regueseros, en su mayoría jóvenes, utilizan esta música como medio de expresión, y para adquirir ganancias. La mayoría de ellos provenían principalmente de las ciudades de Panamá y Colón ${ }^{28}$. Entre los regueseros más destacados de esta etapa se pueden mencionar a Jiffith Donaldson (Chichoman), Fernando Brown (Nando Boon), Edgardo Franco ${ }^{29}$ (El General) y Ernesto Brown (El Apache Ness). Como ya se señaló, las canciones de estos señores eran traducciones de las producciones jamaicanas ${ }^{30}$, adaptadas a la realidad social panameña ${ }^{31}$, también muchos de ellos escribieron canciones propias o tomaron de otros géneros, para ampliar el repertorio musical

\footnotetext{
${ }^{28}$ En su mayoría estos intérpretes son descendientes de inmigrantes antillanos.

${ }^{29}$ Edgardo Franco (El General)

${ }^{30}$ Por ejemplo: She Pum Pum (del cantante jamaicano Admiral Bayley), fue traducida por Edgardo Franco (El General) en 1988

${ }^{31}$ Mi chica come coco de Ness y Los Sensacionales.

${ }^{32}$ Jiffith Donaldson. Comunicación personal.
} 
del reggae. Para efectos ilustrativos se resalta una afirmación de Jiffith Donaldson (Chichoman), quién en una entrevista afirmó:

"A mi me gustaba cantar canciones en balada y tomé algunas letras de canciones como 'Navidad Sin ti' de los Bukis y la pase al ritmo de reggae." ${ }^{32}$

\section{¿El perreo, el rapeo, la plena o reggae panameño?}

En general, se afirma que realmente lo que hacían los intérpretes panameños de reggae, era rapear, que en el argot musical quiere decir rimar, y la música tenía concordancias rítmicas con la rima. En sus inicios el género era denominado reggae, pero al cantarse en español se quiso distinguir identificándolo con un nombre que de alguna manera indicara su origen panameño ${ }^{33}$.

\section{Ilustración 1}

Discoteca móvil "Revelación Biekito". Calle 4ta, Provincia de Colón. Año 1994.

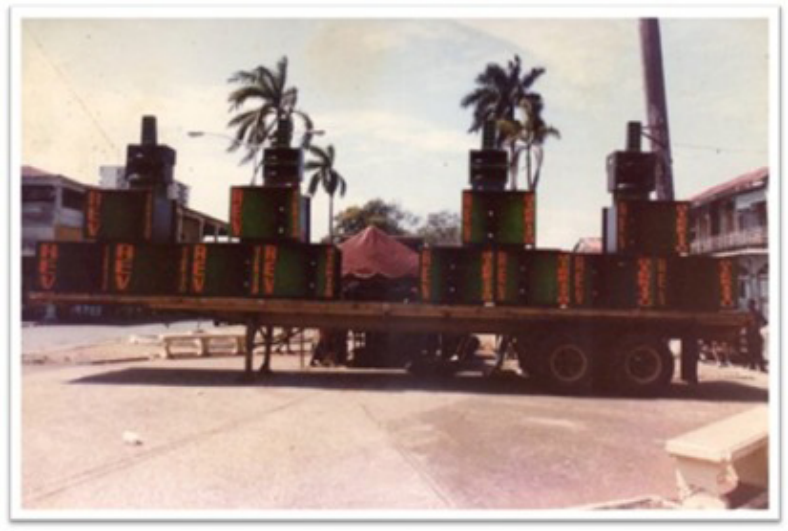

Foto: Francisco Quinn.

“...para esa época en el argot de los Disc Jockeys (Colocador de Discos) se consideraba plena a toda música que fuese contagiosa y que 'pegara'”(... $)^{34}$
Los intérpretes, Disc Jockeys (Colocador de discos) y productores nacionales toman la palabra plena como propia y hoy día se usa como sinónimo de la palabra reggae a lo producido en Panamá. Más tarde la plena comenzó a tomar otros nombres para identificarse, como ejemplo el mote de petroleum jelly ${ }^{35}$.

Se considera que fue el DJs de radio colonense Nestaly Moreno, de la radio emisora La voz del Trópico, la persona que le dio el nombre de $\mathrm{Pe}$ trolium a las canciones de reggae. Ya que para él y los DJs en general que no colocaban este género, las personas o DJs que estaban involucrados con

\section{Ilustración 2}

DJs en discoteca móvil. Finales de los años 80

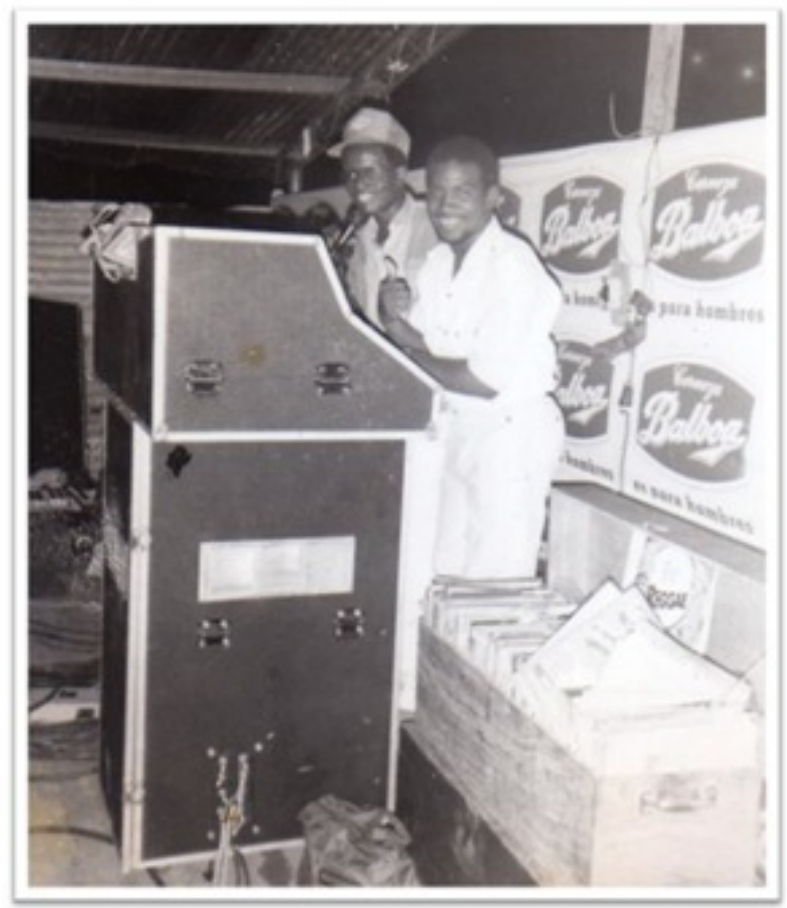

Foto: Francisco Quinn.

\footnotetext{
${ }^{33}$ Un ejemplo claro de la necesidad de nombrar el género por los lugareños es lo que pasa actualmente en Puerto Rico, donde identifican la producción musical del mismo género mediante la denotación de reggaeton.

${ }^{34}$ Francisco Quinn. Productor Musical. Comunicación personal.

${ }^{35}$ Nombre de una pomada para el cabello, lo que sugiere que el reggae panameño es musicalmente pegajoso.

${ }^{36}$ Francisco Quinn. Productor Musical. Comunicación personal.
} 
la propagación de este tipo de música estaban impregnados por la "grasa", parecido a los mecánicos. Haciendo énfasis en la discriminación en cuanto a la procedencia del reggae; ya que era música elaborada por personas de la etnia negra, consideradas por los demás como sucias. ${ }^{36}$

El perreo, es otro de las denominaciones mediante el cual es conocido el reggae nacional y lo usan para indicar la costumbre de los creadores de introducir vulgaridades en sus canciones, es decir, son unos perros, unos ordinarios.

\section{Desarrollo y evolución del reggae panameño}

Con la llegada de este nuevo género y su incorporación al gusto musical de los jóvenes panameños, son los medios de comunicación masiva los que jugaron y siguen jugando un papel muy importante en la difusión posterior, el desarrollo y la evolución de esta música.

Pero, es importante destacar que son las discotecas móviles ${ }^{37}$ a través de sus DJs ${ }^{38}$, las que se encargaron de difundir este género en toda la República, en los llamados toldos populares.

¿En qué formato musical llegaba esta música? " $L a$ música llegaba a Panamá en discos de acetato de 45 revoluciones por minuto o en $L P$, estos discos tenían en la parte anterior, normalmente una canción, $y$ en la posterior, el ritmo. Sobre este ritmo se cantaba y se grababan las canciones panameñas, es por eso que siempre se escuchan diferentes letras sobre un mismo ritmo". ${ }^{39}$

Esto se debe a que en Jamaica la corriente de reggae dancehall hace que proliferen los estudios digitales, que han dado muestra de poseer una mayor eficacia de costos que la generación anterior de estudios de música analógica, y sustentaron las bases para el sonido dancehall digitalizado, sobre el cual los artistas superponen un ritmo.

Esta innovación técnica, trajo como consecuencia directa el crecimiento de los álbumes monorrítmicos, en que diferentes artistas, en algunos casos en número de hasta 15 , superponían sus voces en la misma pista de rhythm (ritmo). Esta técnica se afianzó a lo largo de toda esta época, en especial para el consumo local. ¿A quién iba dirigida, esta música durante esta primera etapa?

Desde su génesis, el reggae panameño fue encasillado como música de maleantes y negros; esto se debe a que era producido por los miembros de grupos socialmente marginados de las ciudades de Panamá y Colón, y que efectivamente, esta música era cantada por miembros de la etnia negra que vivían en barrios populares.

Si sólo se analizan los lugares donde en sus inicios se bailaba la plena, se puede corroborar a quiénes iba originalmente dirigida esta música. Los toldos populares de la ciudad de Panamá, en efecto, estuvieron ubicados en barrios menos favorecidos como son los casos de: "El Sesteo" y "Nuevas glorias soberanas" en San Miguelito, "Los Compas" en Pedregal, "Mi linda Gloria” en Juan Díaz; mientras que en Colón destacan, el "Club Náutico Caribe"; "Super Centro Caribe", "Las Américas", "El Lida", y "Taco de oro".

Esto se apoya también en que los temas, por otra parte, que venían de Jamaica, eran de carácter muy controversial ya que hablaban de sexo y drogas, por ejemplo:

\footnotetext{
${ }^{37}$ Entre las discotecas móviles podemos mencionar están Electro Disco, Sony Tape y Revelación Biequito, Estudio 54 y Vibración Positiva.

${ }^{38} \mathrm{DJs}$
} 


"(..)Best friend give you gun (tu mejor
amigo te regala el arma)
best friend give you a gun
because some men nowadays (porque
los hombres de se muestran pechones)
put up them chest
hablan de que tiene más que los demás)
talk how much them have
than them...”

Sin embargo, en Panamá, en su mayoría, describían realidades sociales de la época; por ejemplo:

"Amigo no te quedes sin bailar.

Todo el mundo está mirando.

$Y$ si te paras en la esquina tú verás

a todo el mundo saltando.

Tú lo que quieres es bailar.

Tú lo que quieres es gozar..." ${ }^{40}$

"Al baile yo quiero entrar $y$

los policías no me dejan pasar.

¿Por qué?

Dicen que yo soy menor de edad.
De cómo del lugar me le voy a escapar" ${ }^{41}$

El reggae en sus inicios enfrentó muchos problemas de aceptación por parte de las personas adultas, quienes consideraban esta música como denigrante y prohibían a sus hijos escucharla. El repudio hacia esta música se ve reflejado en los horarios y la frecuencia de emisoras que las reproducían. Las primeras emisoras en lanzar al aire este tipo de música fueron la $F M 99$ y BB Stereo; sólo se les permitía colocarla después de las 11 de la noche. Igualmente, en la ciudad de Colón la primera emisora en tocar este tipo de música fue La Voz del Trópico y sólo era autorizada los fines de semana y después de la 11 de la noche.

\section{¡Seguimos con las manos arriba!}

Como se dijo anteriormente, la difusión del reggae en Panamá se debe primordialmente a los medios de comunicación masivos, siendo las principales ejecutoras del cambio y del mantenimiento del reggae panameño, las emisoras radiales.

En 1993 salió al aire la emisora Fabulosa Stereo en los 100,5 FM. Esta emisora marcó un nuevo período en la difusión y producción de la música reggae en Panamá, al cubrir toda la República en diferentes frecuencias moduladas, incorporando, como parte importante de su programación, el reggae panameño y jamaiquino. Hasta ese momento, el reggae se escuchaba con mayor asiduidad en las ciudades de Panamá y Colón. En el interior, la única emisora que se escuchaba y colocaba dentro de su programación reggae, era

\footnotetext{
${ }^{39}$ Francisco Quinn. Productor Musical. Comunicación personal.

${ }^{40}$ Fernando Brown. "Nando Boon"

${ }^{41}$ Aldo Vargas "Aldo Ranks"

${ }^{42}$ No solo al género, también a la radiodifusión en general pero esos cambios no serán detallados en este estudio por que no son parte medular de esta investigación

${ }^{43}$ Los DJs trabajan como un equipo humano conformado por dos personas por turno, la idea fundamental de la pareja es que uno mezclara y el otro animara o amenizara, igual como operan en los toques o bailes populares.
} 
Stereo Azul 101,1 F.M., en un programa llamado "El Show de Sony Tape" (programa de una discoteca móvil), la cual se transmitía en horas de la tarde.

Entre los cambios ${ }^{42}$ más significativos que aporta a este género la emisora Fabulosa Stereo, está el hecho de que ya no sólo se programaban los discos de reggae en horas de la noche, sino también en horas de la tarde, a partir de las 2:00 p.m.

Contrataron como locutores a DJs que trabajaban en discotecas móviles, y de forma estable para que se encargasen de dicha programación y trasladaran a la radio su manera de trabajar en las discotecas. ${ }^{43}$

Gracias al reggae, a las radios emisoras panameñas se incorporan otras reglas para los locutores:

Emitir sonidos o dar repiques, superponiendo sus voces a la música grabada, lo que le estaba prohibido al locutor hasta este momento ${ }^{44}$. Esta innovación va acompañada de otros cambios, como el de involucrar al oyente a la programación mediante saludos y comentarios, que cubren desde problemas amorosos hasta opiniones politicas.

Otra de las aportaciones al género de la emisora Fabulosa Stereo son las producciones de discos compactos o CD nacionales ${ }^{45}$. Las primeras producciones musicales fueron realizadas por Rodney Clark. Se puede afirmar, sin lugar a dudas, que R. Clark es actualmente el representante máximo de las producciones de reggae en Panamá, junto a Carlos Correa y Rodolfo De León. Los tres se dieron a conocer a través del grupo de reggae "Los Fabulositos", como parte de una estrategia publicitaria para la emisora y para el reggae. La aceptación de la emisora Fabulosa Stereo entre el público juvenil fue buena, dando comienzo a una nueva etapa para el género en Panamá.

1995 fue un año de ampliaciones para la música reggae, ya que sale al aire otra emisora con el mismo patrón de Fabulosa Stereo, Super Q90,5 FM. Esta emisora pertenece a la Cadena Radial La Exitosa. Al igual que Fabulosa Stereo, Super $Q$ hace del reggae una parte importante de su programación, y a ella se trasladan los DJs, Rodney Clark y Rodolfo De León.

\section{Panamá produce su propio reggae}

Panamá intenta en esta etapa a dar pasos para lograr una mayor calidad y variedad en esta música y a producir su propio reggae. Entre los productores más destacados de este género se encuentra el Sr. Rodney Clark, conocido en el mundo artístico como El Chombo; sus producciones fueron las primeras en exportarse ${ }^{46}$. Él afirma que:

\footnotetext{
${ }^{44}$ Esta tradición es característica predominante de la música jamaicana, y que comienza a verse con el surgimiento del reggae dance hall.

${ }^{45}$ Las primeras producciones de reggae nacional las realizaron el Sr. Ramón "Pucho" Bustamante y el Sr. Luis "Wicho” Phillips (este último dueño de la discoteca móvil Electro Disco). Sin embargo, se hace énfasis en las producciones realizadas por la emisora Fabulosa Stereo por que es aquí donde se le toma con un fin de mercado.

${ }^{46}$ Una producción que fue muy importante a nivel internacional fue el CD. Cuentos de la Cripta

${ }^{47}$ Rodney Clark, ha realizado más de 35 producciones de reggae y ha manejado unos 85 cantantes (entre los que están panameños, jamaicanos y puertorriqueños).

${ }^{48}$ Aris De Icaza hijo. Gerente General. Cadena Radial La Exitosa.

${ }^{49}$ Rodney Clark. Comunicación personal.

${ }^{50}$ Por ejemplo: "Suban las manos", "Con las manos arriba” y comentarios vulgares que ellos llaman "coros", que en la mayoría de los casos están compuesta por frases de contenido soez; entre los mas utilizados están "agarrame la pinga", "yo te saco la chucha” "vete pa' la verga", "a que yo te lo rompo", "policía hijo de puta de la verga si me agarras yo te mando pa' la verga", "sácale la chucha", y en muchas ocasiones antecedidas por canciones de reggae, ya en español, ya en inglés.
} 
"Mientras que el reggae lo produzcan panameños, lo canten panameños y lo bailen panameños, el género vivirâ" ${ }^{47}$

Igualmente, para Aris De Icaza Jr:

"El reggae en Panamá se ha mantenido porque existen productores nacionales" 48

En Panamá hay cinco productores ejecutivos y siete productores musicales:

"Lo que pasa es que el Productor Ejecutivo es el que decide qué o quién va en el CD y paga los costos de la producción y el Productor Musical es el que hace el trabajo de grabación y fabrica los ritmos" ${ }^{49}$

Sin embargo, es importante destacar que las tandas de reggae tienen sus variantes dependiendo de los lugares donde se reproducen (radio o discoteca). Estas variantes están sujetas a los DJs que animan a los bailadores a través de ciertas expresiones ${ }^{50}$.

\section{Consideraciones finales}

Panamá, por razones históricas, ha utilizado la danza y la música como medios de expresión de su cultura, de quiénes y cómo son los panameños. La música reggae ha constituido el pivote alrededor del cual continúa girando la expresión musical de la juventud panameña contemporánea.

Los ritmos afroantillanos que se han dado a conocer en Panamá no sólo han tenido aceptación por parte de la colonia afroantillana residente en el país, sino que se han desarrollado de una forma autónoma. El desarrollo del reggae en esta tierra ejemplifica claramente un fenómeno que se ha ido repitiendo a lo largo de estos cien años de vida Republicana.

Por otro lado, y saliendo del ámbito panameño no se puede negar que el reggae en español ha sido un género musical que ha despertado muchísimas pasiones y que se ha convertido en la forma de expresarse de muchos jóvenes en América Latina. Con el pasar de los años ha adquirido más seguidores que se sienten atraídos por un ritmo que consideran como "pegajoso".

Los resultados que arroja esta investigación dan a conocer que desde sus inicios fue importante contar con una estrategia de comercialización y que los primeros cantantes de este género procedían de llamados ghettos de las ciudades terminales de Panamá y Colón. Sin embargo, con el pasar de los tiempos lograron llegar a diferentes públicos dándole cierto reconocimiento dentro de la cultura popular latina.

Panamá es la cuna del reggae en español y esta afirmación ya no se puede poner en tela de juicio; fueron los primeros regueseros panameños que a inicios del 2000 llegaron a Puerto Rico los que inspiraron a cantantes de la talla de Daddy Yankee (Ramón L. Ayala Rodríguez).

La evolución del reggae en español es un evento cultural interesante que habla de cómo un extracto de la sociedad se puede analizar por medio de la música que escucha. Actualmente hay programas radiales y televisivos exclusivos para difundir el reggae en español o dancehall. Esa constante adaptación ha ayudado a la permanencia de este género. 


\section{Referencias}

Arosemena, J. (1855). El Estado Federal de Panamá. En: Justo Arosemena: Patria y Federación.

Ed. N. Castro. La Habana: Casa de las Américas. pp. $213-296$.

Bohannam, Paul. (2009) Para raros nosotros. Introducción a la Antropología Cultural. Editorial Akal. Madrid.

Bosch, J. (1981). De Cristóbal Colón a Fidel Castro: El Caribe Frontera Imperial. $1^{a}$ Edición. Casa de las Américas. La Habana.

Caja de Ahorros. (1972). Homenaje a Arturo Chino Hassán: Colección de sus Mejores Canciones. Caja de Ahorros, Panamá.

Comunidad Rasta de Panamá. (2000). Manuscrito no Publicado. Mimeo.

Diez C., L.A. (1981). Los Negros Antillanos en Panamá. $1^{a}$ Edición. Talleres de la Imprenta Julio Mercado Rudas. Panamá.

Fortune, A. (1976). Presencia africana en la música panameña, en Actas del Primer Congreso Internacional de Folklorología. Editora de La Nación. Panamá.

García Hudson, M. (2012). El bolero panameño en el Caribe en Revista Cátedra: revista del Centro de Investigaciones de la Facultad de Humanidades. No. 12. Universidad de Panamá. Centro de Investigaciones de la Facultad de Humanidades, Panamá.

Geertz, C. (1997). La interpretación de la cultura. 8a Edición. Editorial Gedisa. S.A. España.

Giovannetti, J. (2001). Sonidos de Condena. Sociabilidad, historia y politica en la música reggae de Jamaica. Editorial Siglo XXI. México.

Hobsbawm, E.J. (1998). La Era del Imperio, 1875 1914: Grupo Editorial Planeta. Buenos Aires.
Leymarie, I. (1985). La música latinoamericana, ritmos y danzas de un continente. Ediciones Grupo Zeta. Madrid

Maloney, G. (1992). Las raíces del reggae. (Artículo en tres entregas). El Panamá América. 28, 29,30 de junio.

Newton, V. (1995). Los hombres del "Silver Roll". Migración Antillana en Panamá 1850-1914. Caudasía Editores. Panamá.

Ulloa Brenes, G. (2007). Hipótesis sobre la subversión religiosa en el Rastafarismo. Revista Reflexiones 86-1. Páginas 115-126. Costa Rica.

Wolfschoon, E. (1983). Las Manifestaciones Artísticas en Panamá. Tomo 12 de la Biblioteca de la Cultura Panameña. Industria Gráfica S.A. Panamá.

Zabala, I.M. (2000). El Bolero: Historia de un Amor. Celestes Ediciones, S.A. Madrid. 